\title{
New HCV drugs trigger race for more tolerable therapies
}

The approval this year of the first directacting antiviral drugs for the hepatitis $C$ virus has ushered in a new era of treatment. Since the mid-May launch of Incivek (telaprevir) and Victrelis (boceprevir) - both of which disrupt viral replication by inhibiting HCV's protease protein-physicians have rapidly been prescribing the pills to many of the estimated 180 million people worldwide who are infected with HCV. This is reflected in October earnings reports showing that sales of Incivek reached nearly $\$ 420$ million in the third quarter of this year alone, which puts it on pace to become the fastest blockbuster in the history of the pharmaceutical industry.

But Incivek, from Vertex Pharmaceuticals of Cambridge, Massachusetts, and Victrelis, from Merck of Whitehouse Station, New Jersey, currently have a catch. Each medicine must be taken with a broad-acting antiviral pill called ribavirin as well as with regular injections of pegylated interferon. Historically, viral clearance occurs in around half of all people who take interferon together with ribavirin, but another $20 \%$ can be cured of their HCV when doctors throw one of the new polymerase inhibitors into the mix. Interferon stimulates the immune system but comes with side effects ranging from flu-like fatigue to severe depression to cardiac arrhythmias. Up to a third of people on the protein ultimately stop the therapy early because of adverse reactions.

Against this backdrop, there was much fanfare over the 1 November announcement by the Princeton, New Jersey-based company Pharmasset that it would initiate the world's first phase 3 clinical study involving an alloral, interferon-free protocol before the end of the year. The 500-person trial will compare a three-month regimen of the company's experimental polymerase inhibitor, PSI-7977, together with ribavirin against a six-month course of interferon plus ribavirin. PSI-7977 works by becoming incorporated into RNA chains being made by HCV, stopping the virus from replicating.

"There's been real concern that we might never be able to get away from interferon entirely, but now we're starting to get an inkling that that might not be the case," says Gary Davis, director of the general and transplant hepatology unit at the Baylor University Medical Center in Dallas.

At the annual meeting of the American Association for the Study of Liver Diseases in San Francisco on 6 November, Pharmasset also presented data from their latest phase 2 trial, which tested once-daily dosing of
PSI-7977 plus ribavirin in 40 people with or without interferon therapy. Even in the trial arm without interferon, all ten study subjects were cured of their infection after 12 weeks, the company reported. Also at the November meeting, Germany's Boehringer Ingelheim, Denmark's Santaris Pharma, Switzerland's Novartis and Georgia state's Inhibitex presented similarly positive phase 2 data from their own interferon-free regimens. A handful of other companies have other experimental drugs in the interferon-free pipeline, too (see 'Have no interferon').

Even Roche-the maker of Pegasys, the leading interferon used in $\mathrm{HCV}$, with global sales approaching $\$ 2$ billion last year-may be looking to developing an interferon-free product. On 17 October, the Swiss drug giant announced that it had purchased Anadys Pharmaceuticals, a San Diego-based drugmaker with a polymerase inhibitor called setrobuvir in phase 2 development, for about \$230 million.

\section{Running interferons}

Richard Smith, Pharmasset's vice president of investor relations and corporate communications, likens the development of the latest generation of $\mathrm{HCV}$ therapies to what happened with HIV treatment protocols in the 1990s. "With the early HIV drugs, patients were taking eight or ten pills a day; now they have much more simplified regimens," he says. "We think that hepatitis C treatments will go the same way and start to move from combinations of interferon and all these other drugs toward a simplified treatment regimen."

But instead of paring down the number of drugs in the HCV cocktail, Jake Liang, chief of the Liver Diseases Branch at the US National Institute of Diabetes and Digestive

Have no interferon: interferon-free HCV therapies in mid- and late-stage development.

\begin{tabular}{|c|c|c|c|}
\hline Phase & Company & Investigational drugs & Drug action \\
\hline 3 & Pharmasset & PSI-7977 & Polymerase inhibitor \\
\hline \multirow[t]{10}{*}{2} & Abbott Laboratories & ABT-450 plus $A B T-333$ or $A B T-072$ & Protease and polymerase inhibitors \\
\hline & Boehringer-Ingelheim & $\mathrm{BI}-201335$ and $\mathrm{BI}-207127$ & Protease and polymerase inhibitors \\
\hline & Bristol-Myers Squibb & BMS-650032 and BMS-790052 & Protease and NS5A inhibitors \\
\hline & Gilead Sciences & $\begin{array}{l}\text { GS-9451, GS-5885 and GS-9190 } \\
\text { (tegobuvir) }\end{array}$ & $\begin{array}{l}\text { Protease, polymerase } \\
\text { and NS5A inhibitors }\end{array}$ \\
\hline & Inhibitex & INX-189 & Polymerase inhibitor \\
\hline & Novartis & DEB025 (alisporivir) & Cyclophilin inhibitor \\
\hline & $\begin{array}{l}\text { Peregrine } \\
\text { Pharmaceuticals }\end{array}$ & Bavituximab & $\begin{array}{l}\text { Phosphatidylserine- } \\
\text { targeted antibody }\end{array}$ \\
\hline & Roche & Danoprevir and R05024048 & Protease and polymerase inhibitors \\
\hline & Santaris & Miravirsen & MicroRNA-122 inhibitor \\
\hline & Vertex & Incivek (telaprevir) and VX-222 & Protease and polymerase inhibitors \\
\hline
\end{tabular}

and Kidney Diseases in Bethesda, Maryland, thinks combinations of multiple agents will be needed to target different aspects of viral infection and replication in order to reduce the chances of HCV developing resistance to a drug regimen. To this end, Chicago-based Abbott Laboratories is developing a four-inone pill that includes the company's ABT-450 protease inhibitor, one of two polymerase inhibitors, ribavirin and Abbott's antiviral pill Norvir (ritonavir), which is commonly used to treat HIV. The company released interim data in October from a pair of trials with a total of 44 participants indicating complete viral clearance in around $90 \%$ of subjects. Meanwhile, Gilead Pharmaceuticals, based in Foster City, California, is also testing a four-drug combo with a similar mix of investigational agents that also includes a drug directed at the nonstructural 5A (NS5A) protein involved in viral replication.

Analysts say the race to develop the first interferon-free treatment is a race to take over the market. "With HIV, we've seen a small handful of drugs dominate the market, and it's become incredibly difficult for any new drugs to compete," says Brian Skorney, an analyst with Brean Murray, Carret \& Co. in New York. "I think you'll see something similar with the hepatitis C market. Whatever drug is first able to get rid of interferon will become the market leader just by being first." And, in the short run, he says, it's a growing market. Health campaigns-led by Merck and Vertex-to diagnose new cases of HCV will probably cause prevalence to rise before it drops. And more tolerable drugs mean more patients with $\mathrm{HCV}$ being treated. "You'll see a pretty substantial increase in the market size once you move to an all-oral treatment," he says.

\section{Sarah C P Williams}

